\title{
Age, Sex and Strain Respond Differently to Acute Ritalin (Methylphenidate) Exposure
}

\author{
Asif A. Kabani, Pamela B. Yang, Nachum Dafny* \\ Department of Neurobiology and Neuroanatomy, University of Texas McGovern Medical School at Houston, 6431 \\ Fannin Street, Houston TX 77030, U.S.A.
}

*Corresponding author: Dr. Nachum Dafny; nachum.dafny@uth.tmc.edu

Received 24 February 2021;

Accepted 24 May 2021;

Published 04 June 2021

\begin{abstract}
The dose-dependent response to variable methylphenidate (MPD) doses on the behavior of male and female adolescent (post-natal day 39) and adult (post-natal day 60) rats of three different genetic strains was studied to examine whether there are sex, age and strain dependent differences in response to MPD. Twenty-four male and twenty-four female groups were used. The 48 groups each had an $\mathrm{N}=8$. The results show that female adolescents and adult rats of Sprague-Dawley (SD) and Spontaneous Hyperactive Rat (SHR) strains were more sensitive to the acute exposure of MPD. Furthermore, female adult rats of the SD, SHR and Wistar-Kyoto (WKY) strains generally responded with greater increase in locomotor activity than the adolescent females of these strains. In the WKY strain, adolescent males tended to experience a greater increase in activity than adult males. Lastly, significant differences in response to MPD also were observed among the three genetic strains. These variable responses to the acute dose of MPD reinforce the need to study the effects of this psychostimulant across the various sexes, ages and strains.
\end{abstract}

Keywords: Methylphenidate, Ritalin, Behavior, Sex, Strain, Age

\section{Introduction}

The vast majority of studies investigating the effect of methylphenidate (MPD) use adult males (only one sex) of a single strain. Since MPD is used in children and adults, in both males and females, it is important to obtain information whether this psychostimulant exerts similar or different effects based on age, sex and strain. In recent years there has been a rapid increase in MPD usage all over the world ${ }^{[1]}$. Furthermore, there has been an increase in the number of preschoolers, adolescents and adults with and without a diagnosis of ADHD using MPD ${ }^{[2,3]}$. However, there have been few studies done on the possible adverse effects produced by psychostimulants on developing female and male brains ${ }^{[4,5,6,7]}$. Furthermore, there is a paucity of research when it comes to the effect of MPD on different strains. For this reason, the present study reports the acute dose response of MPD on female and male, young and adult animals of three different strains, two of which serve as a non-ADHD model.

The neuronal systems mediating behavioral activity in general and in response to psychostimulants are sexually dimorphic and are under the control of genes, pituitary and gonadal hormones $[8,9,10]$. Several reports indicated that there are sex dependent differences in response to psychostimulants ${ }^{[9,11,12,13,14]}$. For example, the use of psychostimulants such as cocaine and methamphetamine in both adult female rodent and human subjects has been associated with a more rapid and robust behavioral sensitization following chronic use when compared to their male counterparts ${ }^{[9,15,16]}$. Further, sex differences in endogenous catecholamine (CA) levels and function have been reported ${ }^{[17,18]}$. Given that the mechanism of action of psychostimulants, such as MPD, is binding to CA transporters and modulating synaptic CA levels, this presents a potential mechanism of the sex-related differences ${ }^{[19,20,21,22,23,24,25]}$. Therefore, it is essential to investigate whether there is a sexual difference in response to MPD in young and adult female and male subjects.

According to a report by the US Department of Health and Human Services, the life-time prevalence of attentiondeficit/hyperactivity disorder (ADHD) in children ages 5-17 was $14.2 \%$ for boys and $6.4 \%$ for girls from $2013-2015^{[26]}$. In the last decade, the use of MPD has increased dramatically ${ }^{[3,27]}$. The consumption of MPD has been seen in children as young as two years old ${ }^{[28]}$. There is growing concern about the potential effects of MPD use in children, given that brain development goes on until young adulthood ${ }^{[6]}$. Lastly, several articles in the literature report the link between psychostimulant use and an increased risk of substance abuse disorder ${ }^{[29,6,30]}$. As a result, it is essential to study the role of MPD use on different ages, especially in those that do not have ADHD.

Studies using various strains of rat, either inbred, such as the spontaneously hypertensive or hyperactive rat (SHR), or outbred, reveal that the genetic differences between strains are important factors on the effect of drugs ${ }^{[31,32,33,34]}$. Animal models 
have been developed to study ADHD and the ability of medications such as MPD to modulate their behavior, including the SHR. The SHR was inbred from the Wistar-Kyoto (WKY) strain, with an initial intent to study hypertension. However, when it was found that these rats exhibited hyperactivity, motor impulsiveness, and impaired attention, the SHR strain was proposed as an ADHD model, with WKY serving as a control ${ }^{[35]}$. Lastly, the SpragueDawley (SD) rat strain has been well studied in experiments with psychostimulants, having been characterized to have sensitization to cocaine and methylphenidate, making it an ideal strain to compare to WKY and SHR rats ${ }^{[36]}$. Furthermore, a study has specifically shown that there are differences in dopamine receptor levels between WKY and SD rats that may affect their responses to psychostimulants ${ }^{[37]}$. Therefore, it is essential to study the effect of MPD on multiple animal strains, such as the three strains used in this investigation. The hypothesis of this study is that the response to MPD is significantly different across age, sex and strain.

\section{Methods}

\section{Animals}

Three hundred and eighty-four adult and adolescent, male and female rats of three strains were studied in this experiment. The three strains utilized were Sprague Dawley (SD), Wistar-Kyoto (WKY) and Spontaneous Hyperactive (Hypertensive) Rats (SHR). The animals were split into groups of 32 animals as depicted in Figure 1. Each of these groups of 32 were divided into four subgroups, each being given a different drug exposure: saline, 0.6 $\mathrm{mg} / \mathrm{kg}$ MPD, $2.5 \mathrm{mg} / \mathrm{kg}$ MPD and $10.0 \mathrm{mg} / \mathrm{kg}$ MPD. All animals were purchased from Harlan Laboratories (Indianapolis, IN, USA). After an acclimation period of 5 to 7 days, each animal was placed in an individual home cage (see Figure 2). The experimental protocol was started on PND 39 for all adolescents and PND 60 for all adults. The home cage served as the test cage, in order to minimize the effect of environment on drug response. The animals were kept in their cages for 5 to 7 days for adaptation prior to the recording sessions. Lights were turned on daily at 6:00 A.M. as part of this acclimation process and turned off at 6:00 P.M. All experimental procedures were approved by University of Texas Health Science Center Animal Welfare Committee (AWC) in accordance with the National Institute of Health Guide for Care and Use of Laboratory Animals.

\section{Protocol}

Three doses of MPD were used $(0,6,2.5 \& 10.0 \mathrm{mg} / \mathrm{kg}$ i.p) were used. These doses were selected from previous MPD dose response experiment started at $0.1 \mathrm{mg} / \mathrm{kg}$ to $50.0 \mathrm{mg} / \mathrm{kg}[38,4,39,40]$. On recording day 1 (RD1) all animals received an intraperitoneal injection of saline. On recording day 2 (RD2) either saline, 0.6 $\mathrm{mg} / \mathrm{kg}, \quad 2.5 \mathrm{mg} / \mathrm{kg}$, or $10.0 \mathrm{mg} / \mathrm{kg}$ MPD was administered intraperitoneally. The MPD was measured as free base and equalized to $0.8 \mathrm{~mL}$ injection volume. All injections were done in the morning at 8:00 A.M. Each recording started immediately post injection and lasted for 120 minutes.

\section{Behavioral Data Acquisition}

The Computerized Animal Activity Monitoring (CAAM) system was used as an open field assay to record the locomotor behavioral activity of the free moving animals (see Figure 2). Open field locomotion behaviors represent the interaction of the whole animal within the experimental situation. The details of the procedure are well established and previously published ${ }^{[41,42,4,5,43,36,40]}$. Each interruption from each sensor was counted and cumulative counts were compiled by the Accuscan Analyzer (Columbus, OH, USA).
The counts were downloaded every 10 minutes to a PC using Outcome and Assessment Information Set (OASIS) data collection software. The OASIS program then organized the beam breaks into several locomotor indices ${ }^{[38,36,40]}$, and transmitted to a PC for statistical analysis.

\section{Behavioral Data Analysis}

For this study six different locomotor behaviors were analyzed: horizontal activity (HA), total distance (TD) traveled, number of discrete movements (NM), number of stereotypic movements (NOS), vertical activity (VA) and rest time (RT). Horizontal activity was calculated as the number of beam interruptions in the lowest level of sensors. Total distance measured the total forward movement in centimeters. The number of discrete movements indicates the sum of separate horizontal movements, whereas the number of stereotypic movements is the number of repetitive movements with at least a 1 second interval between them. Vertical activity was measured as the number of beam breaks in the highest level of sensors. Lastly, rest time was the time the animal spent between beam breaks. Each locomotor activity is regulated by different neuronal circuits. The effect of MPD was evaluated by comparing the counts of each locomotor behavioral index post MPD exposure on RD2 with recording following saline injection on RD1. The student paired t-test was used to compare counts before and after MPD exposure within each group, for each locomotor index. Multifactor Analysis of Variance (ANOVA) with post-hoc analysis using Fisher's LSD test as well as general linear model ANOVA (fixed factor) as appropriate followed by the Bonferroni correction were performed to determine if there were any statistically significant $(\mathrm{p}<0.05)$ differences between different locomotor indices, MPD doses, strains, sexes and ages. The power of ANOVA for this study is estimated to be from 0.83 to 0.94 with a sample size of $\mathrm{N}=8$ for each group and locomotor index.

\section{Results}

\section{Saline Control}

The control groups of animals of each sex, age and genetic strain were recorded for 120 minutes on recording day 1 (RD1) and RD2 following injection of saline. Statistical comparison of all six locomotor indices on RD2 and RD1 was performed, showing no significant difference between the two days. This indicates that animal handling, injection procedures, including the volume of injection (saline) did not have a significant effect on any of six locomotor indices measured. The observation that saline on RD1 was similar to RD2, indicates that recording following saline injection on RD1 in all other treatment groups can be used as a control. During the preliminary portion of this study, animal activity was recorded for 42 consecutive days in two groups: one that received no injections and one that received daily injections of saline ${ }^{[44]}$. It was observed that time, animal handling and daily saline injections did not modulate the animals' locomotor activity significantly (see Figure 3).

\section{MPD effect}

Figure 4 compares the locomotor behavioral activity following MPD injection on recording day 2 (RD2) to the activity on RD1 after saline injection. The figure summarizes the effect of MPD on all six locomotor behavior indices of male adult Wistar-Kyoto (WKY) rats, stratified by the three MPD doses (0.6, 2.5, and 10.0 $\mathrm{mg} / \mathrm{kg}$ ). Each pair of columns represents the activity during the recording session post-saline injection on RD1 and post-MPD exposure on RD2. The figure shows that MPD elicits a dose dependent increase in locomotion, i.e. with increasing doses of 
MPD there was a further significant increase in all locomotion indices aside from rest time $(\mathrm{F}(2,25)=4.28, \mathrm{p}<0.05)$ in which an expected opposite trend was demonstrated. In general, a similar observation was seen in all the other rat groups, with minor nonsignificant fluctuation. However, at the lowest dose $(0.6 \mathrm{mg} / \mathrm{kg}$ MPD), a few groups, mainly those of the WKY strain, exhibited a significant decrease in locomotion after the acute MPD exposure (F $(2,25)=4.28, \mathrm{p}<0.05)$.

The change in the total distance traveled on recording day 1 (RD1) after saline administration and on recording day 2 (RD2) after MPD administration for male (left column of each of the paired histograms) and female (right column of each of the paired histograms) are presented in Figure 5. The change is given as the total distance on RD2 minus the total distance on RD1. The figure summarizes this difference for males and females of both ages, for all three strains and at all three different dosages of MPD. In each of the 9 parts of the figure (A-I), there are four columns presented: adolescent males and females and adult males and females. A total of four comparisons are made in each of these parts: adolescent male versus adolescent female, adult male versus adult female, adolescent male versus adult male and adolescent female versus adult female. In the WKY strain, there was no consistent sex difference or age difference in total distance traveled. In general, adolescent males exhibited significantly greater hyperactivity than adult males across the doses $(\mathrm{F}(2,23)=4.01, \mathrm{p}<0.05)$, with the opposite being seen in females (adults exhibiting more hyperactivity than adolescents), aside from the $2.5 \mathrm{mg} / \mathrm{kg}$ MPD dose. However, for the SHR strain, at the 2.5 and $10.0 \mathrm{mg} / \mathrm{kg}$ MPD doses, the adult and adolescent females exhibited a significantly greater increase when compared to their respective males $(\mathrm{F}(3,46)$ $=4.02, \mathrm{p}<0.05)$, a finding that was seen in all three doses for the SD strain. Furthermore, for the SHR strain, at the $2.5 \mathrm{mg} / \mathrm{kg}$ dose, female adults exhibited greater increases than female adolescents, a trend that was seen significantly at the 0.6 and $2.5 \mathrm{mg} / \mathrm{kg}$ MPD dose for SD rats, and at the $10.0 \mathrm{mg} / \mathrm{kg}$ dose in WKY rats $(\mathrm{F}(2,50)$ $=3.67, \mathrm{p}<0.05)$. Additionally, at the $10.0 \mathrm{mg} / \mathrm{kg}$ dose, female adults trended towards a non-statistically significant greater increase than female adolescents in both SD and SHR rats.

The number of discrete movements following MPD doses of $0.6,2.5$ and $10.0 \mathrm{mg} / \mathrm{kg}$ in young (Figure 6A) and adult (Figure 6B) Sprague-Dawley (SD) females are shown. The three MPD doses all resulted in a significant increase in the number of discrete horizontal movements when compared to saline exposure on recording day $1(\mathrm{~F}(10,83)=14.04, \mathrm{p}<0.05)$. A characteristic dose dependent response was again seen. Moreover, the figure shows that adult female rats responded to the acute exposure of $2.5 \mathrm{mg} / \mathrm{kg}$ MPD with a greater increase in number of movements than the young female rats. This reflects the adult female rats exhibiting a greater sensitivity to the drug than the young female rats.

The MPD dose response curves of the three rat strains (WKY, SHR and SD) used in this study are summarized in Figure 7. Figures 7A-7D represent the adolescent males, adult males, adolescent females, and adult females respectively. Dose dependent differences in MPD response were seen across the three strains. Low dose exposure of MPD in adolescent male rats resulted in minor, non-significant differences between the three rat strains. However, following the injection of $2.5 \mathrm{mg} / \mathrm{kg}$ MPD, the WKY adolescent males responded with significantly increased activity than the corresponding SHR group. This response did not differ significantly from the SD group. Following $10.0 \mathrm{mg} / \mathrm{kg}$ MPD exposure, there was a significant difference between the WKY and SD groups but not between the WKY and SHR groups (Fig 7A). The adult male rats exhibited a different response pattern than the adolescents. Following both the lowest and the highest MPD doses $(0.6$ and $10.0 \mathrm{mg} / \mathrm{kg}$ ) each adult rat group exhibited significantly different responses to the drug. For the low MPD dose, the SD rat group exhibited a greater sensitivity to the drug. In contrast, after the high MPD dose, the WKY rat group was the most sensitive to the drug, with the largest total distance traveled. Following 2.5 $\mathrm{mg} / \mathrm{kg}$ MPD, there was no significant difference between the three strains of adults (Fig 7B). For the adolescent females, the only significant differences were seen at the $10.0 \mathrm{mg} / \mathrm{kg}$ dose, where the SHR group responded with a much greater increase than the SD and WKY rats $(\mathrm{F}(2,23)=4.51, \mathrm{p}<0.05)$. There was no significant difference between the SD and WKY rats at this dose. Different results were seen for the adult females, where significant differences between the strains were seen at all doses. At the 0.6 $\mathrm{mg} / \mathrm{kg}$ dose, the SD rats responded with the greatest increase, with the other two strains exhibiting a decrease in total distance traveled. When exposed to $2.5 \mathrm{mg} / \mathrm{kg}$ MPD, both the SHR and SD groups responded with hyperactivity, whereas the WKY strain exhibited a very minimal increase. Lastly, at the $10.0 \mathrm{mg} / \mathrm{kg}$ dose, the SHR rats exhibited a significantly greater increase $(\mathrm{F}(2,22)=$ $3.91, \mathrm{p}<0.05)$ than both WKY and SD rats, which did not differ significantly. Overall, the WKY rat strain tended to be the most hyperactive in adolescent and adult males, whereas in females it was the SHR strain at certain doses and the SD strain at others.

Comparing the MPD dose response effect on male and female adolescent and adult SD rats shows that both male and female adolescent and adult rats responded with a dose dependent increase in horizontal activity (Figure 8). Furthermore, female adolescent and adult rats were more sensitive to the drug, i.e. exhibiting significantly increased horizontal activity after MPD exposure when compared to male rats in both age groups $(\mathrm{F}(10,21)$ $=4.33, \mathrm{p}<0.05)$.

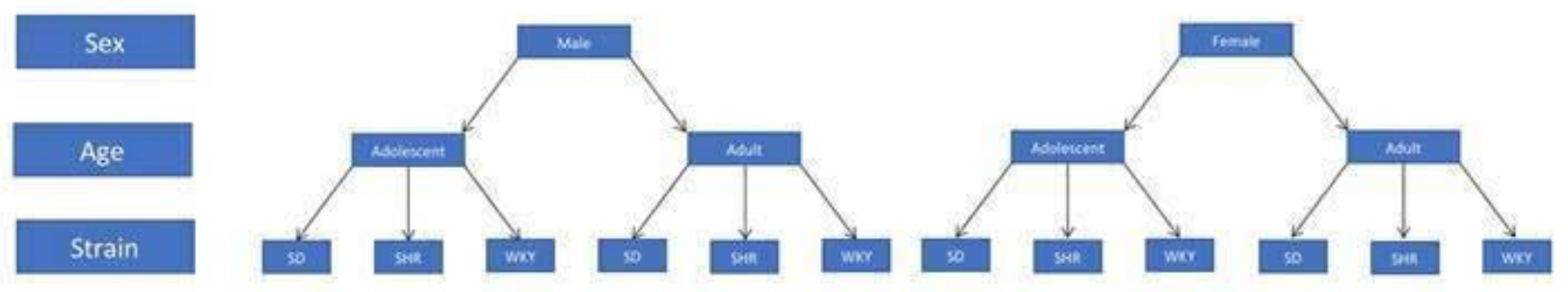

Figure 1: Study Population 
This figure shows the various groups that were studied in this experiment. Each of the 12 groups that are depicted in the bottom row were split into four subgroups by their exposure: saline, $0.6 \mathrm{mg} / \mathrm{kg}, 2.5 \mathrm{mg} / \mathrm{kg}$ and $10.0 \mathrm{mg} / \mathrm{kg} \mathrm{MPD}$. All 48 of these subgroups had an N=8.

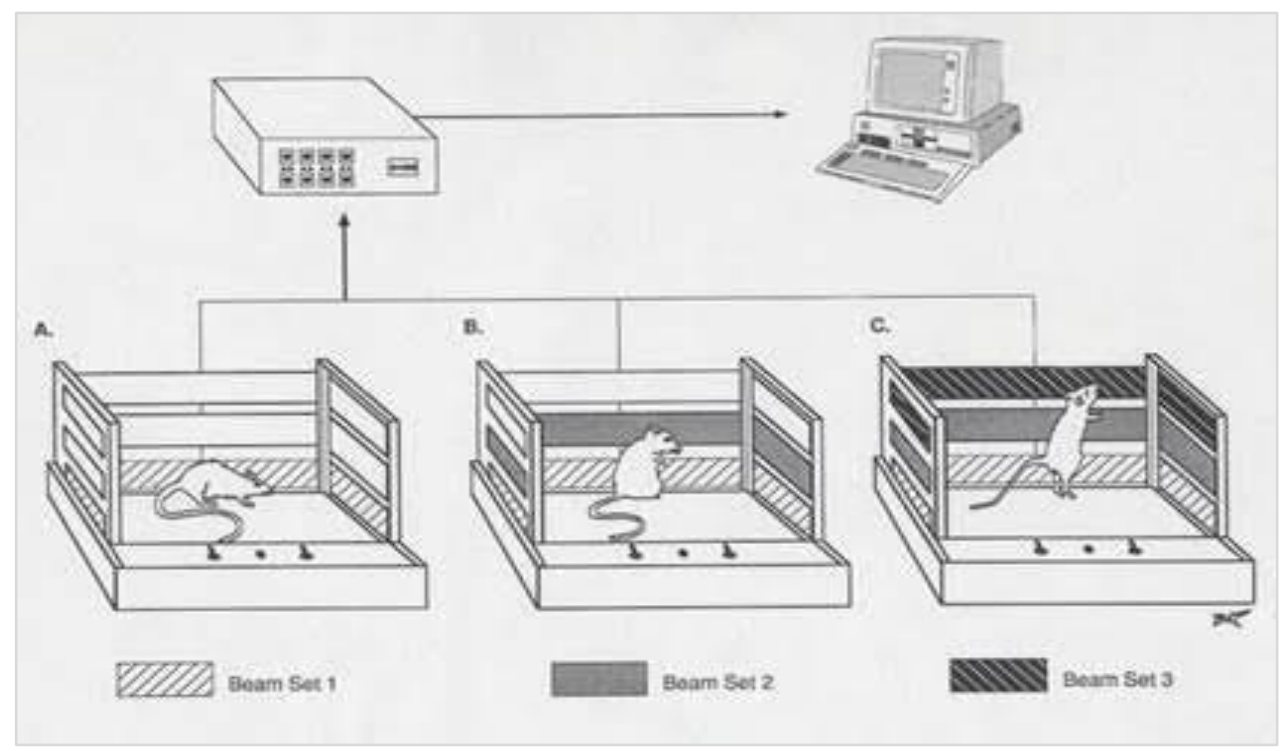

Figure 2: Depiction of the Cage

This figure depicts the cage that was used as home and test cage with three different levels of motion sensors (depicted as per the legend). The cage is $41.5 \mathrm{~cm}$ in length, $41.5 \mathrm{~cm}$ in width, and $31.5 \mathrm{~cm}$ in height. There are 16 infrared beam generators on two of the four sides, with 16 sensors present on the opposite two sides. These beams and their respective sensors are located at 5,10 and $15 \mathrm{~cm}$ above the floor. The lowest level $(5 \mathrm{~cm})$ of sensors records the total movement and total distance as horizontal activity. The middle level $(10 \mathrm{~cm})$ records the number of stereotypic movements, while the highest level $(15 \mathrm{~cm})$ records the vertical activity.

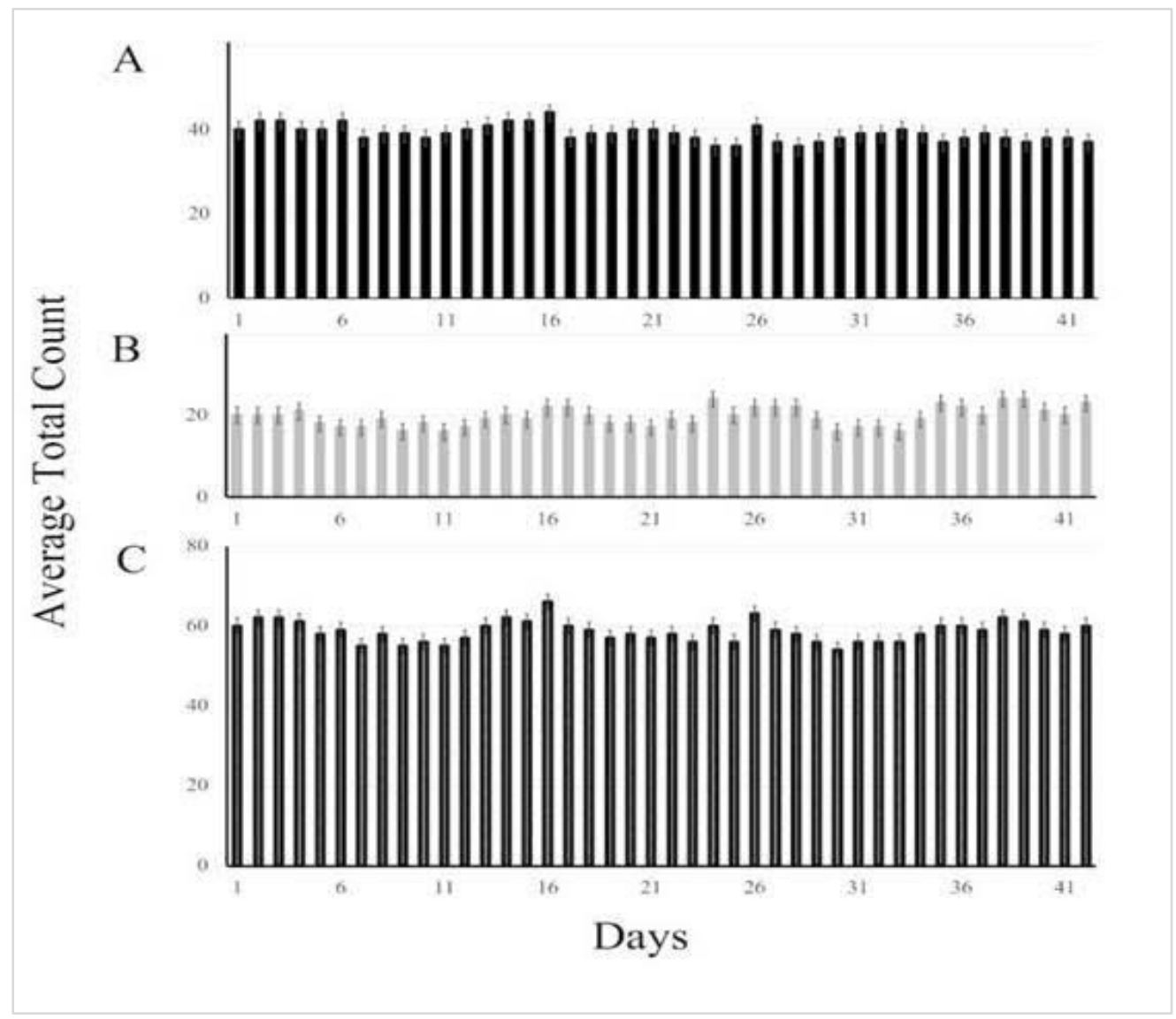

Figure 3: Effect of Saline Injections for Forty-Two Consecutive Days on Locomotor Activity.

The baseline locomotor activity of adult female SD rats $(\mathrm{N}=8)$ was recorded after daily injection with saline for a total of 42 consecutive days. The figure demonstrates the average total horizontal activity count, split into the 12 hours of nighttime (Figure $3 \mathrm{~A}$ ), 12 hours of daytime (Figure 3B) and finally as the full 24-hour cycle (Figure 3C). 


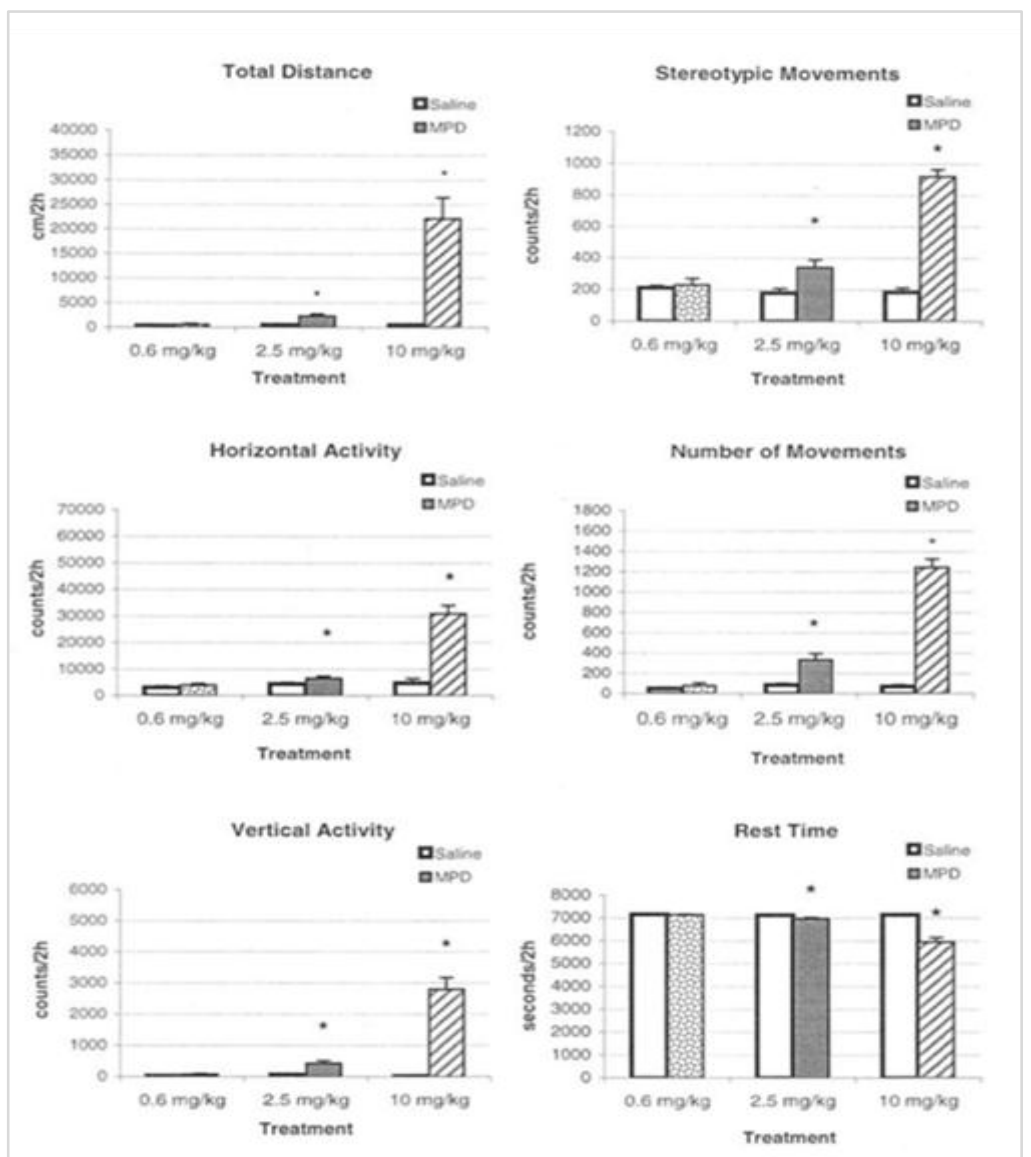

Figure 4: Effect of Varying MPD Dose on Six Locomotor Indices in Adult Male WKY Rats.

The pair of columns depict the value in the two hours post-injection of saline on recording day 1 (RD1) compared to the value post-injection of MPD on recording day 2 (RD2). Values are present as \pm standard error of the mean, with an asterisk $(*)$ depicting a statistically significant $(\mathrm{p}<0.05)$ difference from saline, as determined by the student's t-test.

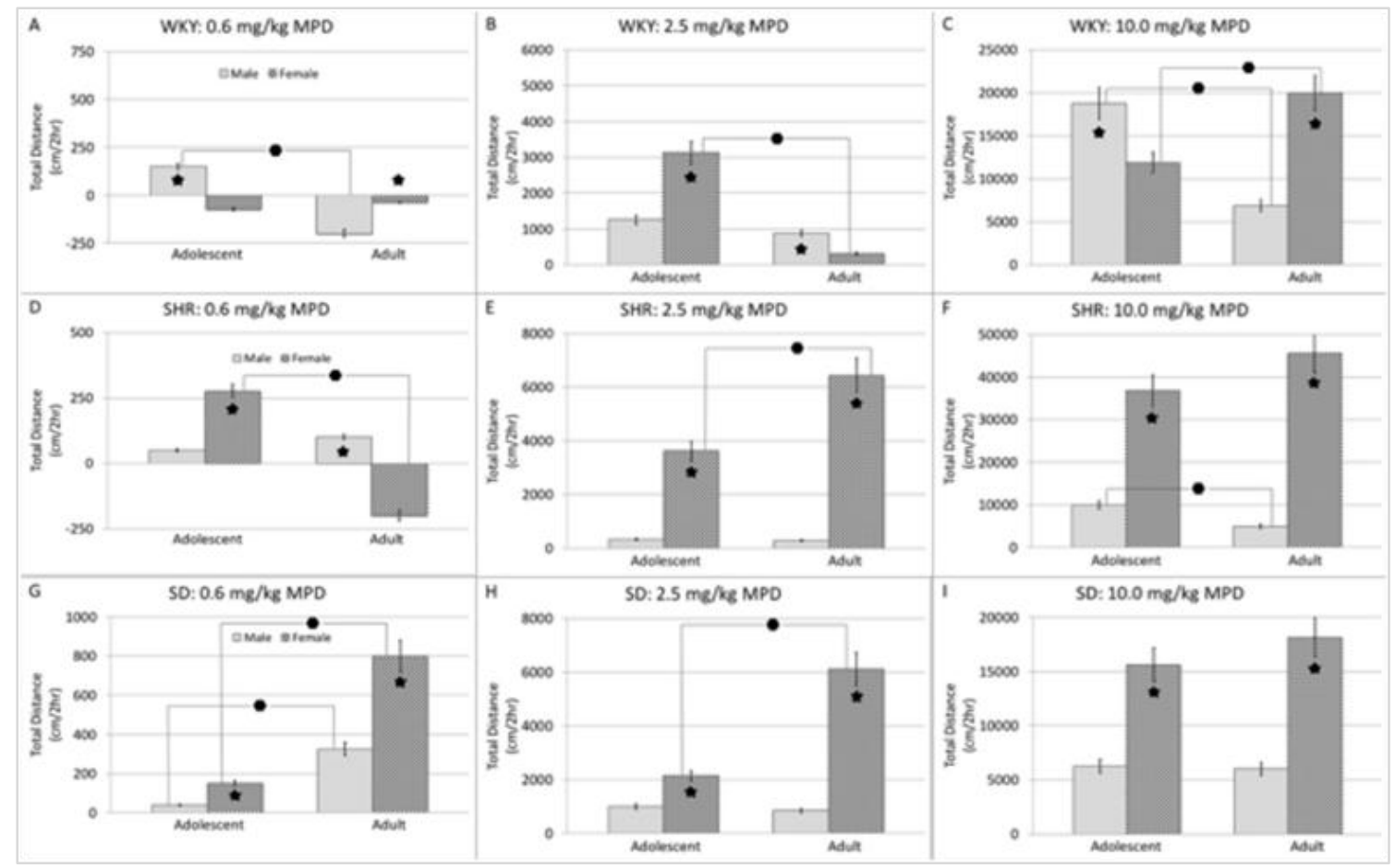

Figure 5: Sex, Age and Strain Differences in Total Distance Traveled after the Acute Administration of Varying Doses of MPD.

Figure 5 compares the acute dose-response in terms of total distance traveled of male (left column) and female (right column) adult and adolescent WKY, SHR, and SD rats to an administration of $0.6,2.5$ and $10.0 \mathrm{mg} / \mathrm{kg}$ MPD, i.p The total distance that is represented is the difference in between the baseline distance traveled on recording day 1 (RD1) after saline administration and the distance traveled on recording day 2 (RD2) after MPD administration. The figure is divided into a total of 9 sections, each representing a different strain and dose of MPD. A 
hexagon $(\square)$ represents a significant difference between adult and adolescents of the same sex, as determined by ANOVA testing with post-hoc Fischer's LSD. A star $(\star)$ represents a significant difference between male and female animals of the same age group, i.e. male adolescents and female adolescents as determined by ANOVA testing with post-hoc Fischer's LSD. The star is placed on or above the column that is the significantly larger in the comparison $(\mathrm{F}(10,83)=14.12, \mathrm{p}<0.05)$.

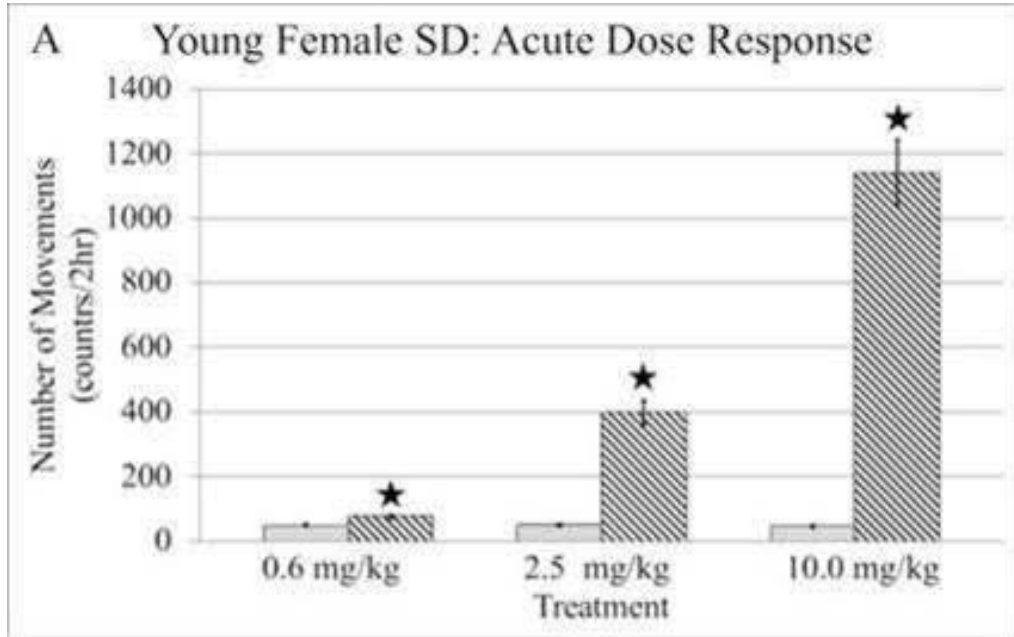

Figure 6: Effect of Acute MPD Exposure on the Number of Discrete Horizontal Movements in Young (Adolescent) and Adult Female SD Rats.

This figure represents the number of discrete horizontal movements (NM) recorded in the two hours following exposure to varying dosages of MPD: $0.6 \mathrm{mg} / \mathrm{kg}, 2.5 \mathrm{mg} / \mathrm{kg}$, and $10.0 \mathrm{mg} / \mathrm{kg}$ in young (Figure 6A) and adult (Figure 6B) SD female rats. The pair of columns compare the number of discrete horizontal movements recorded after saline exposure on recording day 1 (RD1) to the number recorded after MPD exposure on recording day 2 (RD2). A star $(\star)$ above the second bar represents a statistically significant $(F(10,85)=13.97$, p $<0.05)$ difference between the NM measured after saline and MPD exposure, as determined by the student's paired $t$ test. Each subgroup consisted of $n=8$.

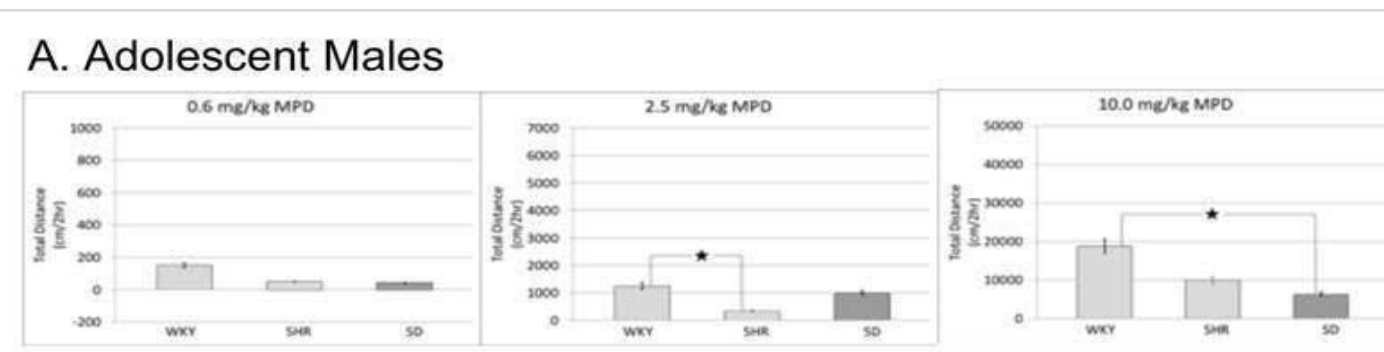

\section{B. Adult Males}
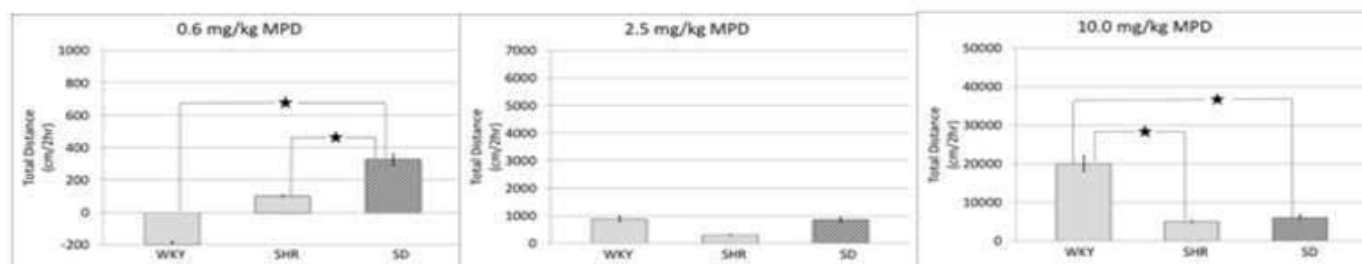

C. Adolescent Females
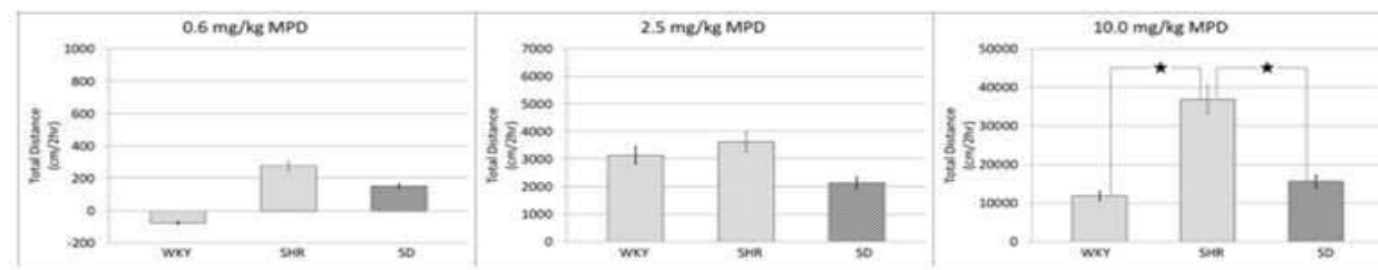

\section{Adult Females}

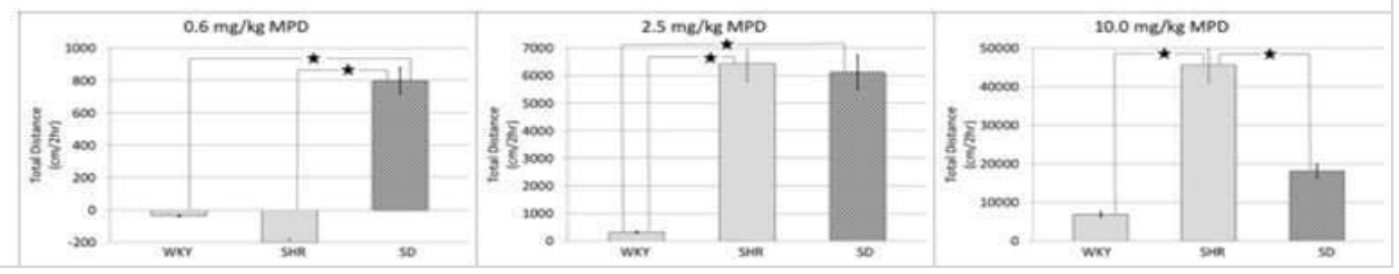

Figure 7: Change in Total Distance after MPD Exposure in Adolescent and Adult Male and Female WKY, SD and SHR Rats. 
This figure summarizes the measurements of total distance traveled in two hours after exposure to varying doses of MPD $(0.6 \mathrm{mg} / \mathrm{kg}, 2.5 \mathrm{mg} / \mathrm{kg}$ and $10 \mathrm{mg} / \mathrm{kg}$ ) in young and adult males and females of the three rat strains (WKY, SHR and SD) used in this study. The measurements depicted are the absolute change from baseline, i.e. the difference between total distance traveled after saline injection on recording day 1 (RD1) and after exposure to MPD on recording day 2 (RD2). Figure 7A represents the adolescent male rats and Figure 7B represents the adult male rats, while Figure $\mathrm{C}$ represents the adolescent female rats and Figure 7D represents the adolescent female rats. A star ( $\star$ ) depicts a statistically significant difference $(\mathrm{F}(10,83)=2.90, \mathrm{p}<0.05)$ between the strains, as determined by multifactor ANOVA with post-hoc analysis with Fischer's LSD test. Each subgroup consisted of $n=8$.

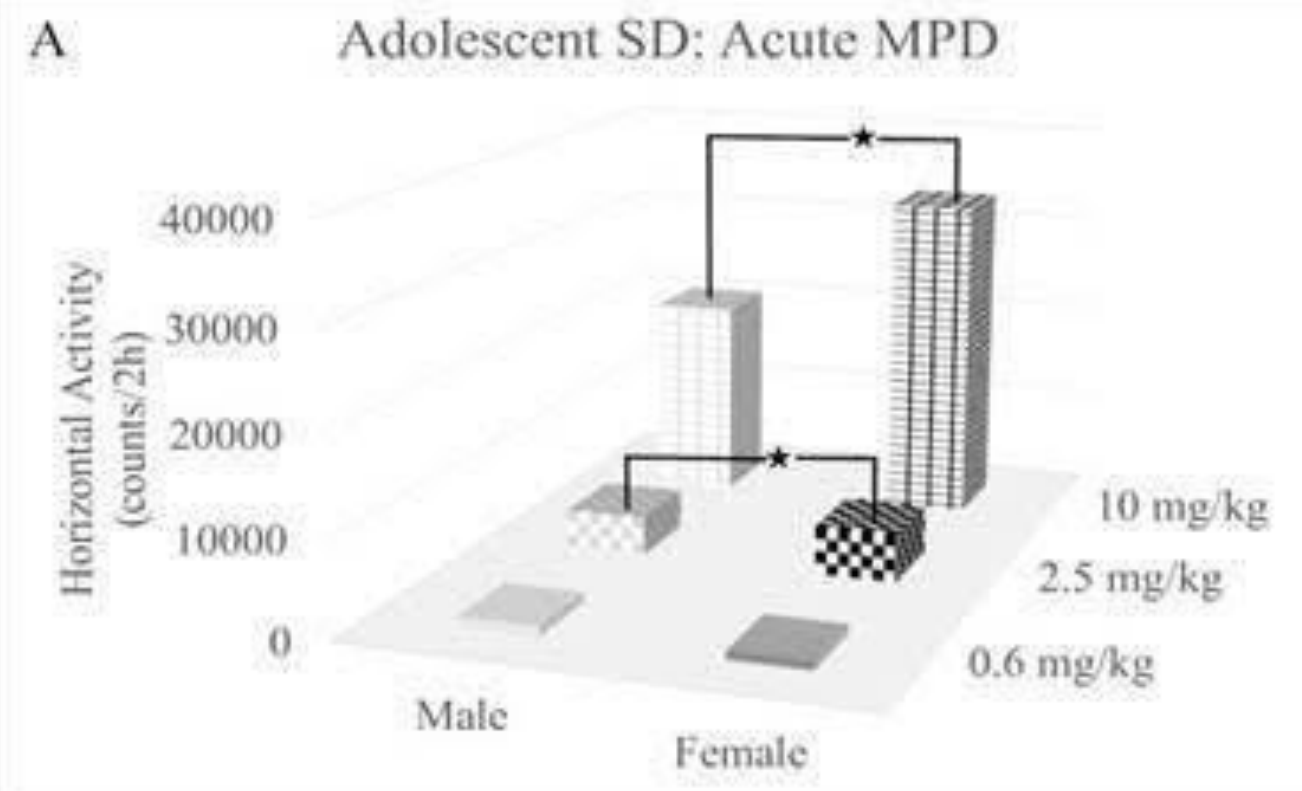

Figure 8: Change in Horizontal Activity after MPD exposure in Adolescent and Adult SD Rats.

Figure 8: Change in Horizontal Activity after MPD exposure in Adolescent and Adult SD Rats. This figure depicts the horizontal activity, as an absolute change from baseline in adolescent (Figure 8A) and adult (Figure 8B) male and female SD rats exposed to $0.6 \mathrm{mg} / \mathrm{kg}, 2.5 \mathrm{mg} / \mathrm{kg}$ and 10 $\mathrm{mg} / \mathrm{kg}$ MPD. The measurements were calculated by subtracting the horizontal activity measured in two hours post-saline injection on recording day 1 (RD1) from the measurement post-MPD injection on recording day 2 (RD2). Values are presented as the mean, with a star ( $\star$ ) representing a statistically significant $(\mathrm{F}(2,25)=5.14, \mathrm{p}<0.05)$ difference between male and female exposed to the same MPD dose, as determined by multifactorial ANOVA with post-hoc Fischer's LSD testing. Each subgroup consisted of $n=8$.

\section{Discussion}

MPD is among the first line medications when it comes to treating social behavioral disorders such as ADHD ${ }^{[45,46,47]}$. Unfortunately, there has been an increase in the use of MPD in people without ADHD and the number of fatalities associated with its misuse has risen to a record level ${ }^{[48,49,50,51,52,3,53,27]}$. Currently, there is widespread prescription and illicit use of methylphenidate (MPD) in persons without ADHD of all ages and both sexes across the world. Given MPD's similar pharmacological profiles to the psychostimulants amphetamine (Amp) and cocaine, further research is warranted regarding the drug's addictive potential ${ }^{[54,29]}$. Previously, studies have shown that cocaine and amphetamine exert different effects based on the age, strain and sex of the subject ${ }^{[55,56,57]}$. It is important to elucidate whether MPD shows similarities or differences to cocaine and Amp in this regard. The objective of this study was to compare the acute effects of 0.6, 2.5 and $10.0 \mathrm{mg} / \mathrm{kg}$ MPD doses on adolescent and adult (age difference) rats of three different strains (genetic difference), while also taking into account the sex of the rat (sex difference). The study confirmed the hypothesis that the dose response of MPD is significantly different across age, sex and strain.

The main findings of this study are as follows. Saline injection and animal handling did not change the six locomotor indices recorded. Consistent activity was observed in adult females over 48 days indicating that the reproductive cycle did not modulate locomotor activity. Acute MPD exposure elicits dose dependent increases in the following five locomotor indices: horizontal activity (HA), total distance (TD) traveled, vertical activity (VA), stereotypic movements (SM), number of stereotypic movements (NOS), and a decrease in rest time (RT). Both young and adult female rats responded to most doses of MPD exposure with more locomotor hyperactivity than young and adult male rats in the SD and SHR rat strains. This trend was not seen in the WKY strain. Additionally, adult female SD and SHR rats responded to most doses of MPD with a greater increase in locomotor activity than young female rats, although the baseline activity in the young rats was higher than adults. This trend was seen to a less significant degree in the WKY strain. Additionally, in the WKY strain the adolescent males tended to be hyperactive when compared to the adult males, although this was not consistent across all three doses. Low dose of MPD $(0.6 \mathrm{mg} / \mathrm{kg})$ in adolescent males and the middle dose of MPD $(2.5 \mathrm{mg} / \mathrm{kg})$ in adult males exerted similar effects on all three rat strains. Similarly, at the low and middle dose of MPD there were similar effects seen in adolescent females. However, strain differences were observed in the adolescent male groups following 2.5 and $10.0 \mathrm{mg} / \mathrm{kg} \mathrm{MPD}$, in the adult male group following 0.6 and $10.0 \mathrm{mg} / \mathrm{kg} \mathrm{MPD}$, in the adolescent female group following $10.0 \mathrm{mg} / \mathrm{kg} \mathrm{MPD}$ and in the adult female groups following all doses of MPD.

The observations of this study indicate that MPD elicits different acute responses in females when compared to males, 
adolescents when compared to adults, and among different rat strains, which is relevant considering the vast increase in MPD use among people in all of these groups. The largest increase in MPD consumption has been seen in young subjects in particular, who are still undergoing normal neuronal plasticity, which may be affected by MPD exposure ${ }^{[49,58,50]}$. This development includes crucial neuroplasticity pertaining to the production and elimination of neuropil. Drug exposure in the adolescent period while the neuropil is dynamically changing may lead to a different response than the same drug exposure in the adult. Furthermore, it is important to consider whether psychostimulant (such as MPD) exposure during development can modulate the neuropil, which includes the synapses that are the target of MPD's action. It has been previously recognized that adolescent rats express an attenuated response to cocaine and Amp, possibly due to a differential neuropil between adults and adolescents ${ }^{[59,60]}$. The findings of this study corroborate previously reported observations of other psychostimulants. There is a further need however, to compare adults that were exposed to MPD in adolescence with those exposed to MPD only in adulthood.

The observations of this study indicate that sex, age, and genetic composition have an influence on the response of animals to MPD, similar to studies that have shown that different pharmacologic agents such as cocaine and Amp exert different effects on specimens of different age, sex and genetic compositions $[61,9,62,13,63,64,65,66,67]$. This difference may be due to differential dopamine receptor expressions in between rat strains, a finding that has been previously reported for WKY, SD and Wistar rats ${ }^{[68,69,37]}$. Furthermore, there may be differences in the metabolism of dopamine or other endogenous catecholamines in different ages, sexes and strains ${ }^{[70]}$. Previously, pharmacogenetic research using genetically modified rodents of different strains has reported that genetic factors are important in how the subject will respond to a drug ${ }^{[71,31,33]}$. The strain differences in response to MPD use observed suggest that the dose needed for an adequate response is variable among the strains. Therefore, it is essential to study the responses to different drugs in different strains and to consider, in a clinical setting, that all humans do not respond identically to MPD pharmacotherapy.

The finding of variable responses by strain also raises the question of which animal strain is the optimal model to study the effect of MPD. In our opinion it depends on the objective. If the goal is to study the effect of MPD on ADHD subjects, the animal model needs to be an animal expressing behaviors similar to $\mathrm{ADHD}$, such as the spontaneous hyperactive rat ${ }^{[72,35,73]}$. However, the widespread use of MPD for cognitive enhancement and recreation among healthy children and young adults without ADHD makes it important to study the properties of MPD on ordinary animal models such as Sprague Dawley or Wistar-Kyoto rats.

Several studies report sex dependent differences in response to drugs and psychostimulants ${ }^{[74,75,76,77,78]}$. The neuronal systems mediating the behavioral responses to both drugs in general and psychostimulants are reported to be sexually dimorphic. These systems are suggested to be under the control of a subject's genetics and the endocrine system ${ }^{[8,10]}$. Gonadal hormones, in particular, enhance the neurochemical responses to psychostimulant administration ${ }^{[9,10]}$. Studies have also reported that sex differences in response to drug exposure are due to sex differences in metabolism ${ }^{[18,79,80]}$. Other studies have shown that adult females express more severe symptoms of drug dependence as well as a more robust and rapid behavioral response to acute Amp and cocaine exposure when compared to males ${ }^{[9,71,14,81]}$. For example, female adult SHR strain rats have an impaired vesicular storage of dopamine and their dorsal and ventral striatum contain a 5 -fold over production and elimination of dopamine D1 and D2 receptors than males ${ }^{[17]}$, which may explain sex and strain differences in response to psychostimulants. None of the above studies compare young females to young males, as was done in this study. Generally, female subjects in our study exhibited a greater increase in locomotor behavior following MPD exposure than males.

Our study does have multiple limitations that represent areas for further research. For one, our experiment solely looks at the acute behavioral response to MPD. Although we found significant differences in just this first exposure, we believe much more can be gained from looking at a chronic exposure to MPD, as we would then be able to make conclusions about the differences in tolerance and sensitization in the various animal groups we studied. Additionally, many studies have shown the concordance between behavioral and electrophysiologic data from brain structures implicated in the reward pathway ${ }^{[41,4,5]}$. This presents another area for comparison between sex, age and strain. Furthermore, the effect of social isolation, as our rats were housed in individual cages, presents another variable to be explored. Studies have shown the ability of social isolation to modulate behavior and cause metabolic changes with respect to dopamine ${ }^{[82,83,84]}$. While our rats were given enrichment materials as part of their social milieu, this is a factor that could have played a role in the differential response between adult and adolescent rats, and therefore should be further investigated.

\section{Conclusion}

The behavioral response to the MPD dose response protocol in this experiment was variable between animals of different sexes, ages and genetic strains. The adult and adolescent females were more sensitive to the effects of MPD in the SD and SHR strains. Adult females were generally more sensitive than adolescents to MPD in all the strains. Adolescent male WKY rats tended to be more sensitive than adults. Further strain differences were seen in various doses groups when separated by age and sex. These differences are consistent with previous reports of similar differences with other psychostimulants and MPD and include comparisons that have not been reported thus far in the literature. Overall, we confirmed our hypothesis that there are differences in response to MPD based on age, sex and strain.

\section{Acknowledgements}

This work was supported by the National Institutes of Health ROIDA0272220 grant. Dr. J Sack comments on the manuscript is appreciated.

\section{References}

[1] Sharpe, K., 2014. Medication: the smart-pill oversell. Nature 506, 146-148. https://doi.org/10.1038/506146a

[2] Bruchmüller, K., Margraf, J., Schneider, S., 2012. Is ADHD diagnosed in accord with diagnostic criteria? Overdiagnosis and influence of client gender on diagnosis. J. Consult. Clin. Psychol. 80, 128-138. https://doi.org/10.1037/a0026582

[3] McHugh, R.K., Nielsen, S., Weiss, R.D., 2015. Prescription drug abuse: From epidemiology to public 
policy. J. Subst. Abuse Treat. 48, 1-7. https://doi.org/10.1016/j.jsat.2014.08.004

[4] Frolov, A., Reyes-Vasquez, C., Dafny, N., 2015. Behavioral and neuronal recording of the nucleus accumbens in adolescent rats following acute and repetitive exposure to methylphenidate. J. Neurophysiol. 113, 369-379. https://doi.org/10.1152/jn.00633.2013

[5] Karim, T.J., Reyes-Vazquez, C., Dafny, N., 2017. Comparison of the VTA and LC response to methylphenidate: a concomitant behavioral and neuronal study of adolescent male rats. J. Neurophysiol. jn.00145.2017. https://doi.org/10.1152/jn.00145.2017

[6] Levin, F.R., Kleber, H.D., 1995. Attention-deficit hyperactivity disorder and substance abuse: relationships and implications for treatment. Harv.Rev. Psychiatry 2, 246-258.

[7] Rowson, S.A., Foster, S.L., Weinshenker, D., Neigh, G.N., 2018. Locomotor sensitization to cocaine in adolescent and adult female Wistar rats. Behav. Brain Res. 0-1. https://doi.org/10.1016/J.BBR.2018.04.035

[8] Berger, D.F., Sagvolden, T., 1998. Sex differences in operant discrimination behaviour in an animal model of attention-deficit hyperactivity disorder. Behav. Brain Res. 94, 73-82. https://doi.org/10.1016/S01664328(97)00171-X

[9] Booze, R.M., Wood, M.L., Welch, M.A., Berry, S., Mactutus, C.F., 1999. Estrous cyclicity and behavioral sensitization in female rats following repeated intravenous cocaine administration. Pharmacol. Biochem. Behav. 64, 605-10.

[10] Kelly, S.J., Ostrowski, N.L., Wilson, M.A., 1999. Gender Differences in Brain and Behavior. Pharmacol. Biochem. Behav. 64, 655-664. https://doi.org/10.1016/S00913057(99)00167-7

[11] Chelaru, M.I., Yang, P.B., Dafny, N., 2012. Sex differences in the behavioral response to methylphenidate in three adolescent rat strains (WKY, SHR, SD). Behav. Brain Res. 226, 8-17. https://doi.org/10.1016/j.bbr.2011.08.027

[12] Cornforth, C., Sonuga-Barke, E., Coghill, D., 2010. Stimulant drug effects on attention deficit/hyperactivity disorder: a review of the effects of age and sex of patients. Curr. Pharm. Des. 16, 2424-33. https://doi.org/10.2174/138161210791959827

[13] Dafny, N., Yang, P.B., 2006. The role of age, genotype, sex, and route of acute and chronic administration of methylphenidate: A review of its locomotor effects. Brain Res. Bull. 68, 393-405. https://doi.org/10.1016/j.brainresbull.2005.10.005

[14] Glick, S.D., Hinds, P.A., 1984. Sex Differences in Sensitization to Cocaine-Induced Rotation. Eur. J. Pharmacol. 99, 119-121.

[15] Griffin, M.L., 1989. A Comparison of Male and Female Cocaine Abusers. Arch. Gen. Psychiatry 46, 122. https://doi.org/10.1001/archpsyc.1989.01810020024005

[16] Kosten, T.A., Gawin, F.H., Kosten, T.R., Rounsaville, B.J., 1993. Gender differences in cocaine use and treatment response. J. Subst. Abuse Treat. 10, 63-66. https://doi.org/10.1016/0740-5472(93)90100-G

[17] Andersen, S.L., Teicher, M.H., 2000. Sex differences in dopamine receptors and their relevance to ADHD Sex differences in dopamine receptors and their relevance to
ADHD. Neurosci. Biobehav. Rev. 24, 137-141. https://doi.org/10.1016/S0149-7634(99)00044-5

[18] Becker, J.B., 1999. Gender differences in dopaminergic function in striatum and nucleus accumbens. Pharmacol. Biochem. Behav. 64, 803-812. https://doi.org/10.1016/S0091-3057(99)00168-9

[19] Gatley, S.J., Volkow, N.D., Gifford, A.N., Fowler, J.S., Dewey, S.L., Ding, Y.S., Logan, J., 1999. Dopaminetransporter occupancy after intravenous doses of cocaine and methylphenidate in mice and humans. Psychopharmacology (Berl). 146, 93-100. https://doi.org/10.1007/s002130051093

[20] Kuczenski, R., Segal, D.S., 2001. Locomotor effects of acute and repeated threshold doses of amphetamine and methylphenidate: relative roles of dopamine and norepinephrine. J. Pharmacol. Exp. Ther. 296, 876-883.

[21] Nestler, E.J., 2001. Molecular basis of neural plasticity underlying addiction. Nat. Rev. Neurosci. 2, 119-128.

[22] Rezvani, A.H., Levin, E.D., 2004. Adolescent and adult rats respond differently to nicotine and alcohol: Motor activity and body temperature. Int. J. Dev. Neurosci. 22, 349-354. https://doi.org/10.1016/j.ijdevneu.2004.03.007

[23] Solanto, M. V., 1998. Neuropsychopharmacological mechanisms of stimulant drug action in attention-deficit hyperactivity disorder: A review and integration. Behav. Brain Res. 94, 127-152. https://doi.org/10.1016/S01664328(97)00175-7

[24] Volkow, N.D., Ding, Y.S., Fowler, J.S., Wang, G.J., Logan, J., Gatley, J.S., Dewey, S., Ashby, C., Liebermann, J., Hitzemann, R., Wolf, A.P., 1995. Is Methylphenidate Like Cocaine?: Studies on Their Pharmacokinetics and Distribution in the Human Brain. Arch. Gen. Psychiatry 52, 456-463. https://doi.org/10.1001/archpsyc.1995.03950180042006

[25] Volkow, N.D., Wang, G.J., Fowler, J.S., Ding, Y.S., 2005. Imaging the effects of methylphenidate on brain dopamine: New model on its therapeutic actions for attention-deficit/hyperactivity disorder. Biol. Psychiatry. https://doi.org/10.1016/j.biopsych.2004.11.006

[26] National Center for Health Statistics, 2017. Health, United States, 2016: With chartbook on long-term trends in health. Cent. Dis. Control 314-317.

[27] Volkow, N.D., Swanson, J.M., 2013. Adult Attention Deficit-Hyperactivity Disorder. N. Engl. J. Med. 369, 1935-1944. https://doi.org/10.1056/NEJMcp1212625

[28] Zito, J.M., Safer, D., DosReis, S., Gardner, J., Boles, M., Lynch, F., 2000. Trends in the Prescribing of Psychotropic Medications to Preschoolers. JAMA 283, 1025-1030. https://doi.org/10.1001/jama.283.8.1025

[29] Kollins, S.H., MacDonald, E.K., Rush, C.R., 2001. Assessing the abuse potential of methylphenidate in nonhuman and human subjects: A review. Pharmacol. Biochem. Behav. 68, 611-627. https://doi.org/10.1016/S0091-3057(01)00464-6

[30] Vendruscolo, L.F., Izídio, G.S., Takahashi, R.N., Ramos, A., 2008. Chronic methylphenidate treatment during adolescence increases anxiety-related behaviors and ethanol drinking in adult spontaneously hypertensive rats. Behav. Pharmacol. 19, 21-27. https://doi.org/10.1097/FBP.0b013e3282f3cfbe

[31] George, F.R., Porrino, L.J., Ritz, M.C., Goldberg, S.R., 1991. Inbred rat strain comparisons indicate different sites of action for cocaine and amphetamine locomotor 
stimulant effects. Psychopharmacology (Berl). 104, 457462. https://doi.org/10.1007/BF02245649

[32] López-Rubalcava, C., Lucki, I., 2000. Strain differences in the behavioral effects of antidepressant drugs in the rat forced swimming test. Neuropsychopharmacology. 22, 191-199. https://doi.org/10.1016/S0893-133X(99)001001

[33] Lucki, I., Dalvi, A., Mayorga, A.J., 2001. Sensitivity to the effects of pharmacologically selective antidepressants in different strains of mice. Psychopharmacology (Berl). 155, 315-322. https://doi.org/10.1007/s002130100694

[34] Phillips, T.J., 1997. Behavior genetics of drug sensitization. Crit. Rev. Neurobiol. 11, 21-33. https://doi.org/10.1615/CritRevNeurobiol.v11.i1.20

[35] Sagvolden, T., 2000. Behavioral validation of the spontaneously hypertensive rat (SHR) as an animal model of attention-deficit/hyperactivity disorder (AD/HD). Neurosci. Biobehav. Rev. 24, 31-39. https://doi.org/10.1016/S0149-7634(99)00058-5

[36] Yang, P.B., Amini, B., Swann, A.C., Dafny, N., 2003. Strain differences in the behavioral responses of male rats to chronically administered methylphenidate. Brain Res. 971, 139-152. https://doi.org/10.1016/S00068993(02)04240-3

[37] Zamudio, S., Fregoso, T., Miranda, A., De La Cruz, F., Flores, G., 2005. Strain differences of dopamine receptor levels and dopamine related behaviors in rats. Brain Res. Bull. 65 , 339-347. https://doi.org/10.1016/j.brainresbull.2005.01.009

[38] Amini, B., Yang, P.B., Swann, A.C., Dafny, N., 2004. Differential locomotor responses in male rats from three strains to acute methylphenidate. Int. J. Neurosci. 114, 1063-1084. https://doi.org/10.1080/00207450490475526

[39] Venkataraman, S., Claussen, C., Dafny, N., 2017. D1 and D2 specific dopamine antagonist modulate the caudate nucleus neuronal responses to chronic methylphenidate exposure. J. Neural Transm. 124, 159-170. https://doi.org/10.1007/s00702-016-1647-x

[40] Yang, P.B., Atkins, K.D., Dafny, N., 2011. Behavioral sensitization and cross-sensitization between methylphenidate amphetamine, and 3,4methylenedioxymethamphetamine (MDMA) in female SD rats. Eur. J. Pharmacol. 661, 72-85. https://doi.org/10.1016/j.ejphar.2011.04.035

[41] Claussen, C.M., Chong, S.L., Dafny, N., 2014. Nucleus accumbens neuronal activity correlates to the animal's behavioral response to acute and chronic methylphenidate. Physiol. Behav. 129, 85-94. https://doi.org/10.1016/j.physbeh.2014.02.024

[42] Dafny, N., 2014. Does Methylphenidate ( MPD ) Have the Potential to Become Drug of Abuse? Biochem. Pharmacol. 4, 1-4. https://doi.org/10.4172/21670501.1000156

[43] Venkataraman, S.S., Claussen, C., Joseph, M., Dafny, N., 2017. Concomitant behavioral and PFC neuronal activity recorded following dose-response protocol of MPD in adult male rats. Brain Res. Bull. 130, 125-137. https://doi.org/10.1016/j.brainresbull.2017.01.008

[44] Dafny, N., 2015. The Characteristics of Methylphenidate on Animal Behavior. Pharm. Anal. Acta 6, 6-10. https://doi.org/10.4172/21532435.1000404
[45] Accardo, P., Blondis, T.A., 2001. What's All the Fuss About Ritalin? J. Pediatr. 138, 6-9. https://doi.org/10.1067/mpd.2001.111505

[46] McCabe, S.E., West, B.T., 2013. Medical and nonmedical use of prescription stimulants: Results from a national multicohort study. J. Am. Acad. Child Adolesc. $\begin{array}{lll}\text { Psychiatry } & \text { 52, }\end{array}$ https://doi.org/10.1016/j.jaac.2013.09.005

[47] Upadhyaya, H.P., Rose, K., Wang, W., O'Rourke, K., Sullivan, B., Deas, D., Brady, K.T., 2005. AttentionDeficit/Hyperactivity Disorder, Medication Treatment, and Substance Use Patterns Among Adolescents and Young Adults. J. Child Adolesc. Psychopharmacol. 15, 799-809. https://doi.org/10.1089/cap.2005.15.799

[48] Cantrell, F.L., Ogera, P., Mallett, P., Mcintyre, I.M., 2014. Fatal oral methylphenidate intoxication with postmortem concentrations. J. Forensic Sci. 59, 847-849. https://doi.org/10.1111/1556-4029.12389

[49] Fond, G., Micoulaud-Franchi, J.A., Brunel, L., Macgregor, A., Miot, S., Lopez, R., Richieri, R., Abbar, M., Lancon, C., Repantis, D., 2015. Innovative mechanisms of action for pharmaceutical cognitive enhancement: A systematic review. Psychiatry Res. 229, 12-20. https://doi.org/10.1016/j.psychres.2015.07.006

[50] Hildt, E., Lieb, K., Bagusat, C., Franke, A.G., 2015. Reflections on Addiction in Students Using Stimulants for Neuroenhancement: A Preliminary Interview Study. Biomed Res. Int. 2015. https://doi.org/10.1155/2015/621075

[51] Levine, B., Caplan, Y.H., Kauffman, G., 1986. Fatality resulting from methylphenidate overdose. J. Anal. Toxicol. 10, 209-210. https://doi.org/10.1093/jat/10.5.209

[52] Massello, W., Carpenter, D. a, 1999. A fatality due to the intranasal abuse of methylphenidate (Ritalin). J. Forensic Sci. 44, 220-1. https://doi.org/10.1520/JFS14440J

[53] Volkow, N.D., Morales, M., 2015. The Brain on Drugs: From Reward to Addiction. Cell 162, 712-725. https://doi.org/10.1016/j.cell.2015.07.046

[54] Calipari, E.S., Ferris, M.J., Melchior, J.R., Bermejo, K., Salahpour, A., Roberts, D.C.S., Jones, S.R., 2014. Methylphenidate and cocaine self-administration produce distinct dopamine terminal alterations. Addict. Biol. 19, 145-155.https://doi.org/10.1111/j.13691600.2012.00456.x

[55] Šlamberová, R., Mikulecká, A., Pometlová, M., Schutová, B., Hrubá, L., Deykun, K., 2011. Sex differences in social interaction of methamphetaminetreated rats. Behav. Pharmacol. 22, 617-623. https://doi.org/10.1097/FBP.0b013e32834afea4

[56] Tendilla-Beltrán, H., Arroyo-García, L.E., Diaz, A., Camacho-Abrego, I., de la Cruz, F., Rodríguez-Moreno, A., Flores, G., 2016. The effects of amphetamine exposure on juvenile rats on the neuronal morphology of the limbic system at prepubertal, pubertal and postpubertal ages. J. Chem. Neuroanat. 77, 68-77. https://doi.org/10.1016/j.jchemneu.2016.05.004

[57] Zombeck, J.A., Swearingen, S.P., Rhodes, J.S., 2010. Acute locomotor responses to cocaine in adolescents vs. adults from four divergent inbred mouse strains. Genes, Brain Behav. 9, 892-898. https://doi.org/10.1111/j.1601183X.2010.00630.x 
[58] Greely, H., Sahakian, B., Harris, J., Kessler, R.C., Gazzaniga, M., Campbell, P., Farah, M.J., 2013. Towards responsible use of cognitive-enhancing drugs by the healthy. Nanotechnology, Brain, Futur. 456, 235245. https://doi.org/10.1007/978-94-007-1787-9_14

[59] Laviola, G., Wood, R.D., Kuhn, C., Francis, R., Spear, Li.P., 1995. Cocaine Sensitization in Periadolescent and Adult Rats. J. Pharmacol. Exp. Ther. 275, 345-357.

[60] Spear, L.P., Brake, S.C., 1983. Periadolescence: Agedependent behavior and psychopharmacological responsivity in rats. Dev. Psychobiol. 16, 83-109. https://doi.org/10.1002/dev.420160203

[61] Adriani, W., Laviola, G., 2003. Elevated levels of impulsivity and reduced place conditioning with damphetamine: Two behavioral features of adolescence in mice. Behav. Neurosci. https://doi.org/10.1037/07357044.117.4.695

[62] Bowman, Brian P.; Kuhn, C.M. (Department of P.U.M.C., 1996. Age-Related Differences in the Chronic and Acute Response to Cocaine. Dev. Psychobiol. 29, 597-611.

[63] Kharas N, Yang PB, Robles T, Sanchez A, Dafny N. 2019a. Sex differences in the intensity of crosssensitization between methylphenidate and amphetamine in adolescent rats. Physiol Behav. 202:77-86. doi:10.1016/j.physbeh.2018.12.021

[64] Kharas N, Yang P, Castro-Alvarado D, Rose K, Dafny N. 2019b. Exposure to methylphenidate in adolescence and adulthood modulates cross-sensitization to amphetamine in adulthood in three genetically variant female rat strains. Behav Brain Res. 362:36-45. doi: 10.1016/j.bbr.2018.12.018.

[65] Segal, D.S., Kuczenski, R., 1987. Individual differences in responsiveness to single and repeated amphetamine administration: behavioral characteristics and neurochemical correlates. J. Pharmacol. Exp. Ther. 242, 917-26.

[66] Somkuwar SS, Kantak KM, Bardo MT, Dwoskin LP. 2016. Adolescent methylphenidate treatment differentially alters adult impulsivity and hyperactivity in the Spontaneously Hypertensive Rat model of ADHD. Pharmacol Biochem Behav. 141:66-77. doi: 10.1016/j.pbb.2015.12.002.

[67] Võikar, V., Kõks, S., Vasar, E., Rauvala, H., 2001. Strain and gender differences in the behavior of mouse lines commonly used in transgenic studies. Physiol. Behav. 72, 271-281. https://doi.org/10.1016/S0031-9384(00)004054

[68] Morganstern, I., Tejani-Butt, S., 2010. Differential patterns of alcohol consumption and dopamine-2 receptor binding in Wistar-Kyoto and Wistar rats. Neurochem. Res. https://doi.org/10.1007/s11064-010-0233-0

[69] Novick, A., Yaroslavsky, I., Tejani-Butt, S., 2008. Strain differences in the expression of dopamine D1 receptors in Wistar-Kyoto (WKY) and Wistar rats. Life Sci. https://doi.org/10.1016/j.lfs.2008.05.006

[70] Somkuwar SS, Darna M, Kantak KM, Dwoskin LP. 2013. Adolescence methylphenidate treatment in a rodent model of attention deficit/hyperactivity disorder: dopamine transporter function and cellular distribution in adulthood. Biochem Pharmacol. 86(2):309-16. doi: 10.1016/j.bcp.2013.04.013
[71] Cailhol, S., Mormède, P., 1999. Strain and sex differences in the locomotor response and behavioral sensitization to cocaine in hyperactive rats. Brain Res. 842, 200-205. https://doi.org/10.1016/S00068993(99)01742-4

[72] Okamato, K., Aoki, K., 1963. Development of a Strain of Spontaneously Hypertensive Rats. Jpn. Circ. J. 27, 282 293. https://doi.org/10.1253/jcj.27.282

[73] Sagvolden, T., Johansen, E.B., Wøien, G., Walaas, S.I., Storm-Mathisen, J., Bergersen, L.H., Hvalby, Ø., Jensen, V., Aase, H., Russell, V.A., Killeen, P.R., DasBanerjee, T., Middleton, F.A., Faraone, S. V., 2009. The spontaneously hypertensive rat model of ADHD - The importance of selecting the appropriate reference strain. Neuropharmacology $\quad 57, \quad 619-626$. https://doi.org/10.1016/j.neuropharm.2009.08.004

[74] Biederman, J., Faraone, S. V., Spencer, T., Wilens, T., Mick, E., Lapey, K.A., 1994. Gender differences in a sample of adults with attention deficit hyperactivity disorder. Psychiatry Res. 53, 13-29. https://doi.org/10.1016/0165-1781(94)90092-2

[75] Camp, D.M., Robinson, T.E., 1988. Susceptibility to sensitization. I. Sex differences in the enduring effects of chronic d-amphetamine treatment on locomotion, stereotyped behavior and brain monoamines. Behav. Brain Res. 30, 55-68. https://doi.org/10.1016/01664328(88)90008-3

[76] Lynch, W.J., Carroll, M.E., 1999. Sex differences in the acquisition of intravenously self-administered cocaine and heroin in rats. Psychopharmacology (Berl). 144, 7782. https://doi.org/10.1007/s002130050979

[77] Ohia-Nwoko, O., Haile, C.N., Kosten, T.A., 2017. Sex differences in the acute locomotor response to methamphetamine in BALB/c mice. Behav. Brain Res. 327, 94-97. https://doi.org/10.1016/j.bbr.2017.03.030

[78] Robison, L.S., Michaelos, M., Gandhi, J., Fricke, D., Miao, E., Lam, C.-Y., Mauceri, A., Vitale, M., Lee, J., Paeng, S., Komatsu, D.E., Hadjiargyrou, M., Thanos, P.K., 2017. Sex Differences in the Physiological and Behavioral Effects of Chronic Oral Methylphenidate Treatment in Rats. Front. Behav. Neurosci. 11, 1-15. https://doi.org/10.3389/fnbeh.2017.00053

[79] Craft, R.M., 2003. Sex differences in drug- and nondrug-induced analgesia. Life Sci. 72, 2675-2688. https://doi.org/10.1016/S0024-3205(03)00178-4

[80] Kato, R., 1975. Sex-Related Differences in Drug Metabolism. Drug Metab. Rev. 3, 1-32. https://doi.org/10.3109/03602537408993737

[81] van Haaren, F., Meyer, M.E., 1991. Sex differences in locomotor activity after acute and chronic cocaine administration. Pharmacol. Biochem. Behav. 39, 923-7. https://doi.org/10.1016/0091-3057(91)90054-6

[82] Karkhanis, A.N., Locke, J.L., Mccool, B.A., Weiner, J.L., Jones, S.R., 2014. Social isolation rearing increases nucleus accumbens dopamine and norepinephrine responses to acute ethanol in adulthood. Alcohol. Clin. Exp. Res. https://doi.org/10.1111/acer.12555

[83] Weiner, J.L., Chappell, A.M., Carter, E., Yorgason, J., Jones, S.R., McCool, B.A., 2013. Adolescent social isolation increases behavioral and neurobiological risk factors of alcoholisminmale long evans rats. Alcohol. Clin. Exp. Res. https://doi.org/http://dx.doi.org/10.1111/acer.12163 
[84] Yorgason, J.T., España, R.A., Konstantopoulos, J.K., Weiner, J.L., Jones, S.R., 2013. Enduring increases in anxiety-like behavior and rapid nucleus accumbens dopamine signaling in socially isolated rats. Eur. J.

Neurosci. https://doi.org/10.1111/ejn.12113 